\title{
Erratum to: Photoprotective compounds from marine organisms
}

\author{
Rajesh P. Rastogi $\cdot$ Richa $\cdot$ Rajeshwar P. Sinha • \\ Shailendra P. Singh · Donat-P. Häder
}

Published online: 24 July 2010

(C) Society for Industrial Microbiology 2010

Erratum to: J Ind Microbiol Biotechnol (2010)

\section{7:537-558}

DOI 10.1007/s10295-010-0718-5

In Fig. 1 of this paper, the Bryophyte should be replaced by Pteridophyte. The corrected figure is attached herewith. In figure 2 legend, the HPDLC should be labeled as HPLC. Our results and conclusions are unaffected by this oversight.

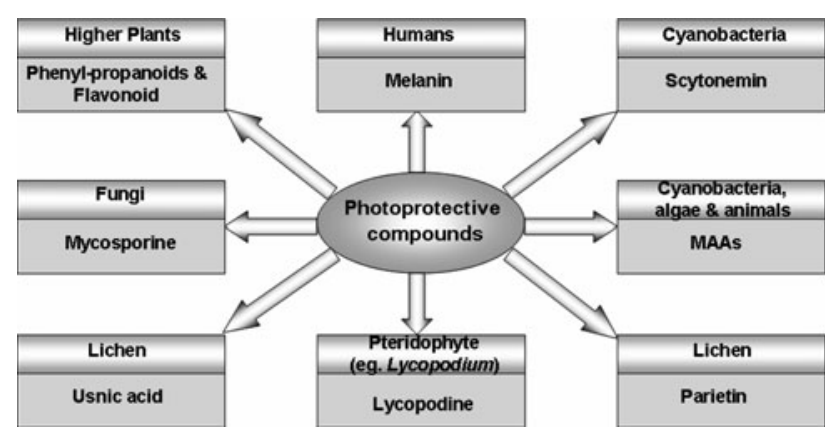

Fig. 1 Occurrence of different photoprotective compounds in diverse organisms

The online version of the original article can be found under doi:10.1007/s10295-010-0718-5.

R. P. Rastogi · Richa - R. P. Sinha

Laboratory of Photobiology and Molecular Microbiology,

Centre of Advanced Study in Botany, Banaras Hindu University,

Varanasi 221005, India

S. P. Singh · D.-P. Häder ( $₫)$

Department of Biology, Friedrich-Alexander University, Erlangen-Nuremberg, Staudtstrasse 5, 91058 Erlangen, Germany

e-mail: dphaeder@biologie.uni-erlangen.de 